\title{
Peak pressure and tidal volume are affected by how the neonatal self-inflating bag is handled
}

\author{
Mariana A. Bassani, ${ }^{1}$ Francisco Mezzacappa Filho, ${ }^{2}$ \\ Maria Regina C. Coppo, ${ }^{3}$ Sérgio T. M. Marba ${ }^{4}$
}

\begin{abstract}
Objective: To evaluate how different ways of handling the neonatal self-inflating bag influence peak pressure and tidal volume.

Methods: This is an experimental study involving 141 different professionals (physicians, resident physicians, physiotherapists, nurses, and nursing technicians), who ventilated an artificial lung, adjusted to simulate the lung of a term neonate, using a self-inflating bag. Each professional handled the ventilator in five different ways: a) using both hands (10 fingers); and, with only one hand, b) five fingers, c) four fingers, d) three fingers, and e) two fingers. Peak pressure and tidal volume data were recorded by the artificial lung equipment.

Results: Both variables showed high variability, from 2.5 to $106.3 \mathrm{cmH}_{2} \mathrm{O}$ (mean $=39.73 \mathrm{cmH}_{2} \mathrm{O} ; 95 \% \mathrm{CI}$ $37.32-42.13$ ) for peak pressure, and from to 4 to $88 \mathrm{~mL}$ (mean $=39.56 \mathrm{~mL} ; 95 \% \mathrm{CI} 36.86-42.25$ ) for tidal volume. There was no significant influence of the profession on any of the variables $(p>0.05)$. However, bag handling significantly influenced both peak pressure and tidal volume $(p<0.0001)$, which were higher when the operator used both hands.

Conclusion: The results indicate that most professionals delivered excessively high peak pressures and tidal volumes, which could increase the risk of barotrauma and volutrauma, especially when both hands were used to ventilate. On the other hand, a small number of professionals delivered insufficient pressure and volume for adequate lung expansion and ventilation. The delivery of inadequate ventilation was not dependent on profession.
\end{abstract}

J Pediatr (Rio J). 2009;85(3):217-222: Neonatal resuscitation, manual lung ventilation, self-inflating bags, barotrauma.

\section{Introduction}

Manual lung ventilation using self-inflating bags is frequently performed by health professionals who provide neonatal intensive care. It is administered to promote oxygenation during anesthesia, ${ }^{1}$ for ventilation during transport inside and outside the hospital setting, ${ }^{2}$ as a respiratory physical therapy technique, ${ }^{3}$ and particularly in cardiopulmonary resuscitation. 2,4-6 However, no consensus has been reached on its use. Although the advantages and disadvantages of using self-inflating bags have been wellreported in the literature, there are no recommendations on the use of such equipment, especially for resuscitation of newborns in the delivery room. ${ }^{6,7}$

1. Mestranda, Saúde da Criança e do Adolescente, Centro de Investigação em Pediatria (CIPED), Universidade Estadual de Campinas (UNICAMP), Campinas, SP, Brazil. Especialista, Fisioterapia em Neonatologia, Centro de Atenção Integral à Saúde da Mulher (CAISM), UNICAMP, Campinas, SP, Brazil. Fisioterapeuta, CAISM, UNICAMP, Campinas, SP, Brazil.

2. Médico neonatologista. Professor assistente, Departamento de Pediatria, CAISM, UNICAMP, Campinas, SP, Brazil.

3. Mestre, Saúde da Criança e do Adolescente, CIPED, UNICAMP, Campinas, SP, Brazil. Fisioterapeuta, CAISM, UNICAMP, Campinas, SP, Brazil.

4. Médico neonatologista, CAISM, UNICAMP, Campinas, SP, Brazil. Professor associado, Departamento de Pediatria, Faculdade de Ciências Médicas, UNICAMP, Campinas, SP, Brazil.

Support: Equipment (artificial lung) supplied by the Center of Biomedical Engineering of UNICAMP.

No conflicts of interest declared concerning the publication of this article.

Suggested citation: Bassani MA, Mezzacappa Filho F, Coppo MR, Marba ST. Peak pressure and tidal volume are affected by how the neonatal self-inflating bag is handled. J Pediatr (Rio J). 2009;85(3):217-222.

Manuscript received Nov 28 2008, accepted for publication Feb 262009.

doi:10.2223/JPED.1886 
Several studies have shown that the ventilatory parameters produced during manual lung ventilation can be highly influenced by many factors, such as profession ${ }^{8,9}$ and professional experience, $8,10,11$ equipment and circuits employed, $3,9,11-13$ hand size, ${ }^{14-16}$ and use of one or both hands. ${ }^{8,15-18}$

In addition, the use of self-inflating resuscitators poses high risk of lung injury, which may later cause chronic lung diseases in childhood. ${ }^{5}$ The risk of barotrauma due to high peak airway pressure is not the only presentation of lung injury caused by the use of self-inflating bags. ${ }^{5,19}$ The use of excessive tidal volumes causes alveolar and lung parenchyma distension, triggering inflammatory cascade, and, as a consequence, injury of the respiratory epithelium, $7,19,20$ mainly in extreme preterm newborns, whose lungs are still undergoing development. ${ }^{20}$ Another concern during manual lung ventilation is the supply of low volumes and pressures, which may be insufficient to promote appropriate ventilation in newborns. ${ }^{21}$ Hypoventilation, which leads to hypoxemia, hypercapnia and acidosis, worsens the patient's clinical condition and prognosis.

Knowledge about the factors that may affect the ventilatory parameters produced during manual lung ventilation with self-inflating bags is extremely important, since it can contribute to technique standardization and, thus, to a safer and more efficient performance, reducing complications and providing patients with better prognosis and shorter hospital stay, and resulting in lower hospital costs.

The objective of the present study was to analyze how the handling of the neonatal manual lung ventilator with a self-inflating bag by different health professionals influences peak pressure and tidal volume.

\section{Methods}

This is an experimental study involving health professionals (physicians, resident physicians, physical therapists, nurses and nursing technicians) who work at the neonatal intensive care unit (NICU) of the Center of Integral Attention to Women's Health (Centro de Atenção Integral à Saúde da Mulher - CAISM) of Universidade Estadual de Campinas (UNICAMP), state of São Paulo, Brazil. After reading and signing the written consent form, volunteers operated a new self-inflating manual lung ventilator, neonatal model, equipped with a silicon bag with maximum capacity of $300 \mathrm{~mL}$ (J. G. Moriya ${ }^{\circledR}$ ) to ventilate an artificial lung (Adult/Infant Ventilator Tester, mod. VT-2, Bio-Tek, Winooski, VT) calibrated and adjusted with airway resistance $\left(200 \mathrm{cmH}_{2} \mathrm{O} / \mathrm{L} / \mathrm{min}\right)$ and lung compliance $\left(0.003 \mathrm{~L} / \mathrm{cmH}_{2} \mathrm{O}\right)$ compatible with physiological values of an intubated term newborn (approximately $3 \mathrm{~kg}$ ). This manual lung ventilator was selected for this study because it is the model most often used at the NICU in our hospital. For this study, there were not reservoir and source of compressed gas connected to the bag. The relief valve, of which activation pressure is equal to or higher than $40 \mathrm{cmH}_{2} \mathrm{O}$ (according to the manufacturer), remained unlocked. The artificial lung used in this study simulates the human lung through adjustment of compliance (provided by a spring system) and resistance (provided by resistors of different diameters) as desired. Flow and pressure transducers, located inside the equipment, convert the information in electrical signal, which is processed and displayed on a liquid crystal screen and/or printed by a built-in printer. This device is in compliance with the norms of the American Society for Testing and Materials F920-93. All tests were performed using the equipment adjusted for barometric pressure of $760 \mathrm{mmHg}$, at $25{ }^{\circ} \mathrm{C}$ of room temperature and $50 \%$ of relative air humidity.

Five different ways of handling the manual lung ventilator were tested (method similar to that employed by GangaZandzou et al.22): a) using both hands (10 fingers); and using one hand: b) five fingers; c) four fingers; d) three fingers; e) two fingers.

The delivered values of peak pressure and tidal volume were computed and recorded by the artificial lung after approximately five cycles provided by each volunteer. An interval of approximately 1 minute was allowed between maneuvers with different ways of handling. The sequence of five ways of handling was previously defined based on a random number table, ${ }^{23}$ and the volunteers were blind to the results during data collection.

This study protocol was approved by the Committee for Ethics in Research of the School of Medicine of UNICAMP.

The statistical analysis was carried out using the software GraphPad Prism version 4.0 (2003). The KolmogorovSmirnov test was used to assess the normality of the sample. The influence of different ways of handling on peak pressure, which had normal distribution, was tested by means of one-way analysis of variance for paired samples, followed by post hoc Bonferroni's test. To analyze the tidal volume, which did not show normal distribution, we used the non-parametric Friedman's test and post hoc Dunn's test. In order to investigate the influence of health professionals' training on these variables, we used one-way analysis of variance for independent samples (parametric), since normal distribution of data was achieved. For the latter analysis, we considered the values provided by each professional group with the five fingers handling, which is most often used in neonatology. Significance level was set at $p<0.05$.

\section{Results}

One hundred and forty-one health professionals who worked at the NICU of CAISM/UNICAMP were included, 
of which 29 were nurses, 11 were assistant physicians or professors, 20 were resident physicians, 49 were nursing technicians, and 32 were physical therapists. We did not find statistically significant influence of profession on the values provided for peak pressure $(p=0.659)$ and tidal volume $(p=0.206)$ (Table 1$)$.

We found that the way of handling the manual lung ventilator had a significant influence $(p<0.0001$ ) on peak pressure and tidal volume when the ventilator was handled with both hands when compared to the use of only one hand. The post hoc test peak pressure values generated using 10 fingers were significantly higher than those resulting from the use of five, four, three $(p<0.01)$ and two $(p<0.001)$ fingers. For tidal volume, we found a significant difference between 10 and four, three and two fingers ( $p<0.01$ ).

Table 2 shows the means, standard deviation, 95\% confidence interval $(95 \% \mathrm{CI})$, and minimum and maximum values for peak pressure and median, interquartile range, $95 \% \mathrm{CI}$, and minimum and maximum values for tidal volume for each different handling, as well as the results of the statistical analyses performed.

It is important to stress that, regardless of the handling maneuver, we could observe a high variability for both variables. Considering all values of peak pressure and tidal volume produced with all different ways of handling by all professionals, the mean peak pressure was $39.73 \mathrm{cmH}_{2} \mathrm{O}$ (95\%CI 37.32-42.13) ranging from 2.5 to $106.3 \mathrm{cmH}_{2} \mathrm{O}$, and the mean value for tidal volume was $39.56 \mathrm{~mL}$ (95\% CI $36.86-42.25$ ) ranging from 4 to $88 \mathrm{~mL}$.

\section{Discussion}

Currently, there are few studies on manual lung ventilation focused on equipment handling and professional influences, particularly with application to neonatology. We found only one study, by Ganga-Zandzou et al., ${ }^{22}$ which approached these factors with regard to ventilation of newborn patients. The authors studied the influence of different ways of handling on respiratory frequency, inspiratory time, tidal volume and peak pressure during manual lung ventilation of a newborn model. Four different ways of handling were analyzed (using five, four, three and two fingers), and the authors found that handling did not influence respiratory frequency, inspiratory time and tidal volume. There was influence of handling only on peak pressure, which was significantly higher with five than with two fingers (38.2 \pm 6.0 vs. $35.5 \pm 6.0$, respectively; $p<0.05)$. There was partial agreement between these results and those found in the present study, which shows that handling significantly affected not only peak pressure, but also tidal volume. It is important to mention that in the present study, a significant difference was observed in the comparison between the use of one and both hands, but not among different ways of handling using only one hand. It is possible that the disagreement between these two studies regarding tidal volume is not due only to the different ways of handling, but also to the size of the sample, which comprised 141 and 19 individuals in the present report and in the study by Ganga-Zandzou et al.,22 respectively. However, both studies found that the pressure values tend to be higher the greater the number of fingers used.

Table 1 - Influence of profession on the variables peak pressure and tidal volume

\begin{tabular}{|c|c|c|c|c|c|}
\hline Variables & Mean \pm SD & $95 \% \mathrm{CI}$ & Minimum & Maximum & $\mathbf{p}$ \\
\hline Peak pressure $\left(\mathrm{cmH}_{2} \mathrm{O}\right)$ & & & & & $0.672^{*}$ \\
\hline Nurse $(n=29)$ & $40.30 \pm 15.11$ & $34.55-46.05$ & 6.50 & 69.80 & \\
\hline Physician $(\mathrm{n}=11)$ & $39.78 \pm 10.26$ & $32.89-46.67$ & 19.70 & 51.30 & \\
\hline Resident physician $(n=20)$ & $35.29 \pm 10.30$ & $30.47-40.11$ & 18.90 & 53.30 & \\
\hline Physical therapist $(\mathrm{n}=32$ ) & $41.36 \pm 17.20$ & $35.16-47.56$ & 8.500 & 89.20 & \\
\hline Nursing technician $(n=49)$ & $40.11 \pm 14.47$ & $32.89-46.67$ & 9.200 & 73.30 & \\
\hline Tidal volume $(\mathrm{mL})$ & & & & & $0.212^{*}$ \\
\hline Nurse $(n=29)$ & $39.38 \pm 14.20$ & $33.98-44.78$ & 4 & 69.00 & \\
\hline Physician $(n=11)$ & $34.91 \pm 12.68$ & $26.39-43.43$ & 17 & 61.00 & \\
\hline Resident physician $(n=20)$ & $36.95 \pm 14.58$ & $30.12-43.78$ & 11 & 65.00 & \\
\hline Physical therapist $(\mathrm{n}=32)$ & $45.25 \pm 20.33$ & $37.92-52.58$ & 4 & 79.00 & \\
\hline Nursing technician $(n=49)$ & $38.06 \pm 15.04$ & $33.74-42.38$ & 8 & 74.00 & \\
\hline
\end{tabular}


Table 2 - Influence of way of handling on peak pressure and tidal volume for a total of 141 volunteers

\begin{tabular}{|c|c|c|c|c|c|}
\hline Variables & Values & $95 \% \mathrm{CI}$ & Minimum & Maximum & $\mathbf{p}$ \\
\hline \multicolumn{6}{|l|}{ Peak pressure $\left(\mathrm{cmH}_{2} \mathrm{O}\right)$, } \\
\hline mean $\pm S D$ & & & & & $<0.0001^{*}$ \\
\hline 10 fingers & $42.71 \pm 16.55$ & $39.96-45.47$ & 6.7 & 106.30 & \\
\hline Five fingers & $42.71 \pm 13.75$ & $37.47-42.05$ & 6.5 & 89.20 & \\
\hline Four fingers & $39.55 \pm 13.76$ & $37.26-41.84$ & 7.9 & 80.60 & \\
\hline Three fingers & $39.50 \pm 14.62$ & $37.07-41.94$ & 2.5 & 105.30 & \\
\hline Two fingers & $37.91 \pm 12.79$ & $35.78-40.04$ & 5.7 & 83.20 & \\
\hline \multicolumn{6}{|l|}{ Tidal volume $(\mathrm{mL})$, } \\
\hline median and quartile range & & & & & $<0.0001^{\dagger}$ \\
\hline 10 fingers & $43.00,30.00-52.00$ & $38.56-44.13$ & 8.00 & 88.00 & \\
\hline Five fingers & $38.00,29.50-51.50$ & $36.87-42.25$ & 4.00 & 79.00 & \\
\hline Four fingers & $38.00,25.00-51.00$ & $36.00-41.12$ & 8.00 & 74.00 & \\
\hline Three fingers & $38.00,25.00-51.00$ & $36.14-41.03$ & 8.00 & 65.00 & \\
\hline Two fingers & $38.00,25.00-51.00$ & $35.27-40.73$ & 4.00 & 74.00 & \\
\hline
\end{tabular}

$95 \% \mathrm{Cl}=95 \%$ confidence interval; SD = standard deviation

* One-way analysis of variance for repeated measures.

$\dagger$ Friedman's test.

Studies that compared the use of one or both hands, that is, five fingers and 10 fingers, respectively, during manual ventilation in adults, showed that the use of both hands resulted in higher tidal volumes.8,15-18 However, Augustine et al., 8 who also analyzed peak pressure, did not find statistically significant differences.

In the present study, we found high variability, with higher values of peak pressure and tidal volume than those recommended in the literature (peak pressure $=30-40$ $\mathrm{cmH}_{2} \mathrm{O} ; 5,7,24$ tidal volume $=5-10 \mathrm{~mL} / \mathrm{kg}^{7}$ ). Similar findings were reported in two studies conducted by Rezende et al. 25,26 that assessed the performance of experienced neonatologists during lung ventilation. These studies evaluated peak pressure, respiratory frequency 25,26 and tidal volume. ${ }^{26}$ In both studies, the authors found high variability of values for peak pressure ${ }^{25,26}$ and tidal volume. ${ }^{26}$ In addition to high variability, they also observed that the values were often higher than those recommended for neonatal resuscitation, with median (25-75\% IQR) of $39.8 \mathrm{cmH}_{2} \mathrm{O}(30.2-47.2)$ and $17.8 \mathrm{~mL} / \mathrm{kg}$ (14.1-22.4) for peak pressure and tidal volume, respectively. The authors pointed out that the technique was more adequate for respiratory frequency, which ranged between 30 and 60 cycles per minute in $65 \%$ of the cases. ${ }^{26}$ In both studies, the relief valve remained locked, which may have contributed to the generation of higher pressures. In the present study, the valve remained in the position of adequate operation (unlocked) and, therefore, it should have released the excess of pressure when reaching $40 \mathrm{cmH}_{2} \mathrm{O}$, although it did not happen. The use of the relief valve is discussed by Finer et al., ${ }^{27}$ whose study demonstrated high variability of pressure when the valve was activated. The authors also stated that these pressure values occasionally exceeded safe limits.

It should be acknowledged that the artificial lung used in the present study did not simulate the thoracic expansion of a newborn. The absence of this visual feedback might have affected the values produced by the professionals.

Based on the high variability and frequent occurrence of values not recommended for neonatal resuscitation, some authors suggest that the use of a manometer connected to the circuit may reduce the variability of the values provided by manual lung ventilation, making the procedure safer and, as a consequence, decreasing possible iatrogenesis. ${ }^{28,29}$ Such an accessory device was not tested in the present study, since we consider that it is only able to record pressure values already delivered, without avoiding the variability of such values due to the different ways of handling of the self-inflating bag.

It should also be observed that a source of compressed gas was not used in the present study. Nevertheless, the use of a source of gas connected to a self-inflating bag with oxygen input directly inside the bag may have an 
important influence on the value of respiratory parameters. ${ }^{30}$ Furthermore, ventilatory parameters may be affected by the use of a reservoir, and by the maximum capacity and compliance of the bag.

In the present study, we could not find influence of the profession on the values of peak pressure and tidal volume resulting from the use of manual lung ventilator. Although comparing professional groups, Hussey et al. ${ }^{13}$ also failed to observe such a correlation. In their study, 35 health professionals were included and divided into two groups: physicians $(n=23)$ and other health professionals ( $n=12$ ) during manual ventilation in an intubated neonatal model. The authors did not find significant differences for any of the variables studied (peak pressure, respiratory frequency and positive end-expiratory pressure) between the groups $(p>0.05)$.

On the other hand, Finer et al. ${ }^{9}$ studied 27 professionals (five respiratory therapists, four neonatologist, five pediatric resident physicians, five nurses, six physicians specialized in neonatology and two nursing practitioners) during manual ventilation (with a mask) in a neonatal model with two different types of circuits, and reported that respiratory therapists provided significantly higher pressures (peak pressure and positive end-expiratory pressure) than the other professional groups $(p<0.0001)$. Augustine et al. ${ }^{8}$ found different results: the highest and lowest tidal volumes were provided by nurses and physicians working at the emergency room, respectively, while the highest and lowest peak pressures were generated by paramedics and respiratory therapists, respectively ( $p<0.05$ ).

The results of the present study indicate that some individuals provided very high peak pressure and tidal volume, which might increase the risk of barotrauma and volutrauma, particularly when both hands were used to ventilate. On the other hand, other professionals provided very low pressures and volumes, and, therefore, insufficient values for adequate lung expansion, causing risk of hypoventilation. Such risks were not dependent on the professional education.

\section{Acknowledgements}

The authors are grateful to the volunteers who participated in this study and to the team of the Clinical Engineering Department of the Center of Biomedical Engineering of UNICAMP, which provided the artificial lung and the necessary training for its correct operation.

\section{References}

1. Spears Jr RS, Yeh A, Fisher DM, Zwass MS. "The educated hand". Can anesthesiologists assess changes in neonatal pulmonary compliance manually? Anesthesiology. 1991;75:693-6.
2. International Liaison Committee on Resuscitation. The International Liaison Committee on Resuscitation (ILCOR) consensus on science with treatment recommendations for pediatric and neonatal patients: pediatric basic and advanced life support. Pediatrics. 2006;117:e955-77.

3. Denehy L. The use of manual hyperinflation in airway clearance. Eur Respir J. 1999;14:958-65.

4. 2005 American Heart Association (AHA) guidelines for cardiopulmonary resuscitation (CPR) and emergency cardiovascular care (ECC) of pediatric and neonatal patients: pediatric basic life support. Pediatrics. 2006;117:e989-1004.

5. Almeida MF, Guinsburg R. Controvérsias em reanimação do recémnascido. J Pediatr (Rio J). 2001;77 Supl 1:S41-52.

6. O'Donnell CP, Davis PG, Morley CJ. Positive pressure ventilation at neonatal resuscitation: review of equipment and international survey of practice. Acta Paediatr. 2004;93:583-8.

7. O'Donnell CP, Davis PG, Morley CJ. Resuscitation of premature infants: what are we doing wrong and can we do better? Biol Neonate. 2003;84:76-82.

8. Augustine JA, Seidel DR, McCabe JB. Ventilation performance using a self-inflating anesthesia bag: effect of operator characteristics. Am J Emerg Med. 1987;5:267-70.

9. Finer NN, Rich W, Craft A, Henderson C. Comparison of methods of bag and mask ventilation for neonatal resuscitation. Resuscitation. 2001;49:299-305.

10. Hodgson C, Carroll S, Denehy L. A survey of manual hyperinflation in Australian hospitals. Aust J Physiother. 1999;45:185-93.

11. Maxwell, Ellis ER. The effects of three manual hyperinflation techniques on pattern of ventilation in a test lung model. Anaesth Intensive Care. 2002;30:283-8.

12. McCarren B, Chow CM. Manual hyperinflation: a description of the technique. Aust J Physiother. 1996;42:203-8.

13. Hussey SG, Ryan CA, Murphy BP. Comparison of three manual ventilation devices using an intubated mannequin. Arch Dis Child Fetal Neonatal Ed. 2004;89:F490-3.

14. Law GD. Effect of hand size on Ve, Vt, and FiO2 during manual resuscitation. Respir Care. 1982,27:1236-8.

15. Hess D, Goff G, Johnson K. The effect of hand size, resuscitator brand, and use of two hands on volumes delivered during adult bag- valve ventilation. Respir Care. 1989;34:805-10.

16. Hess D, Spahr C. An evaluation of volumes delivered by selected adult disposable resuscitators: the effects of hand size, number of hands used, and use of disposable medical gloves. Respir Care. $1990 ; 35: 800-5$.

17. Hess D, Goff G. The effect of two-hand versus one-hand ventilation on volumes delivered during bag-valve ventilation at various resistances and compliances. Respir Care. 1987;32:1025-8.

18. Hess D, Simmons M, Blaukovitch S, Lightner D, Doyle T. An evaluation of the effects of fatigue, impedance, and use of two hands on volumes delivered during bag-valve ventilation. Respir Care. 1993;38:271-5.

19. Dreyfuss D, Saumon G. Ventilator-induced lung injury: lessons from experimental studies. Am J Respir Crit Care Med. 1998; 157:294-323.

20. Almeida MF, Guinsburg R. A reanimação do prematuro extremo em sala de parto. J Pediatr (Rio J). 2005;81:S3-15.

21. Miyoshi M, Guinsburg R. Ventilação pulmonar mecânica convencional no período neonatal. In: Kopelman BI, Santos AMN, Goulart AL, Almeida MF, Miyoshi MH, Guinsburg R, editores. Diagnóstico e tratamento em neonatologia. São Paulo, SP: Atheneu, 2004. p. 149-59.

22. Ganga-Zandzou PS, Diependaele JF, Storme L, Riou Y, Klosowski $\mathrm{S}$, Rakza T, et al. La ventilation à Ambú ${ }^{\circledR}$ chez nouveau-né: une simple question de doigté? Arch Pediatr. 1996;3:1270-2.

23. Paradine $\mathrm{CG}$, Rivett $\mathrm{BH}$. Métodos estatísticos para tecnologias. São Paulo, SP: Polígono da Editora da Universidade de São Paulo; 1974.

24. International Liaison Committee on Resuscitation. 2005 International Consensus on Cardiopulmonary Resuscitation and Emergency Cardiovascular Care Science with Treatment Recommendations. Part 7: Neonatal resuscitation. 2005;67:293-303.

25. Resende JG, Menezes CG, Paula AM, Ferreira AC, Zaconeta CA Silva CA, et al. Evaluation of peak inspiratory pressure and respiratory rate during ventilation of an infant lung model with a self-inflating bag. J Pediatr. 2006;82:359-64. 
26. Resende JG, Zaconeta CA, Ferreira AC, Silva CA, Rodrigues MP Rebello CM, et al. Evaluation of peak inspiratory pressure, tidal volume and respiratory rate during ventilation of premature lambs using a self-inflating bag. J Pediatr (Rio J). 2006;82:279-83.

27. Finer NN, Barrington $\mathrm{KJ}$, Al-Fadley $\mathrm{F}$, Peters $\mathrm{KL}$. Limitations of self-inflating resuscitators. Pediatrics. 1986;77:417-20.

28. Goldstein B, Catlin E, Vetere J, Arguin L. The role of in-line manometers in minimizing peak and mean airway pressure during the hand-regulated ventilation of newborn infants. Respir Care. 1989;34:23-7.

29. Redfern J, Ellis E, Holmes W. The use of a pressure manometer enhances student physiotherapists' performance during manual hyperinflation. Aust J Physiother. 2001;47:121-31.
30. Godoy AC, Vieira RJ, De Capitani EM. Alterações de pico inspiratório e do volume corrente fornecidos por reanimadores manuais com balão auto-inflável em função do fluxo de entrada de oxigênio utilizado. J Bras Pneumol. 2008;34:817-21.

Correspondence:

Mariana A. Bassani

Serviço de Fisioterapia CAISM/UNICAMP

Rua Alexander Fleming, 1101

CEP 13083-970 - Campinas, SP - Brazil

Tel. : +55 (19) 3521.9511, +55 (19) 3521.9428, +55 (19) 3521.9483

E-mail: bassanimariana@hotmail.com 